\title{
A Comparative Analysis of Cognitive and Psychosocial Functioning in Children with Writing Disabilities
}

\author{
Anastasia Alevriadou' ${ }^{1}$, Stergiani Giaouri² \\ ${ }^{1}$ Department of Early Childhood Education, University of Western Macedonia, Florina, Greece \\ ${ }^{2}$ Public Centre for Diagnosis and Support for Children with Special Educational Needs and Disability, Hellenic \\ Ministry of Education, Research and Religious Affairs, Kozani, Greece \\ Email: alevriadoua@gmail.com,stellagiaouri@gmail.com
}

Received 16 December 2015; accepted 2 February 2016; published 5 February 2016

Copyright (C) 2015 by authors and Scientific Research Publishing Inc.

This work is licensed under the Creative Commons Attribution-NonCommercial International License (CC BY-NC).

http://creativecommons.org/licenses/by-nc/4.0/

(c) () \& 8 pen Access

\begin{abstract}
The purpose of the study was to investigate the relationship between the Test of Detection and Investigation of Attention and Concentration, the Test of Executive Function (Simos et al., 2007a,b) and the Test of Psychosocial Adjustment and Self-Report Scale (Hatzichristou et al., 2007), in a sample of 44 Greek $5^{\text {th }}$ grade students with writing disabilities. The results in our study indicated that there were significant Pearson correlations ranged from 0.39 to 0.43 between cognitive, academic and social factors. Additionally, regression analysis indicated that certain scales of the Test of Attention and Concentration have predictive power to emotional sufficiency $(t=2.001, p<0.05)$ and academic self-concept $(t=2.072, p<0.05)$. Further implications of these findings for a schoolbased neuropsychological evaluation and planning of individualized educational interventions are discussed.
\end{abstract}

\section{Keywords}

Cognitive Functions, Psychosocial Functioning, Learning Disabilities, Written Language Process, Critical Measurement Issues

\section{Introduction}

Empirical research (Dunn \& Shapiro, 1999; Merrell, 1998; Olivier \& Steenkamp, 2004; Sideridis \& Padeliadu, 2001) has documented several aspects of cognitive and psychosocial functioning in children with learning dis- 
abilities (LD in one or more academic domains). Although the existing research on LD has not clearly defined a central profile, some characteristics are found to a greater or lesser extent in a number of students. Behavior problems, self-concept, social relationships, and motivational factors, are the topics that have been studied most. Complex cognitive functions of mental flexibility, metacognition, working memory, attention and concentration play a crucial role in written language process as well. Understanding the way these characteristics develop and interact is very important, as it immediately affects the way appropriate teaching approaches should be planned and it also may help researchers and practitioners more accurately screen and treat students with LD.

Furthermore, tests that assess executive functions and the ability to sustain attention, solve verbal and nonverbal problems that require planning, deductive and combining thinking, appear to be increasingly popular when detecting parameters related to learning difficulties, such as written language and reading comprehension problems (Alevriadou \& Giaouri, 2015a, 2015b; Altemeier et al., 2006; Garner, 1988; Hooper et al., 2002). A brief overview of the literature on the different areas of cognitive and psychosocial functions in children with LD indicates the following main findings.

\section{Literature Review}

Data from clinical trials (Altemeier et al., 2006; Lyon et al., 2003; Merrell, 1998) supports the need for simultaneous assessment of cognitive functions (i.e. attention, executive functions) and a child's dimensions of psychosocial behavior for an early and legitimate assessment of his/her learning difficulties. Furthermore, this data includes spotting certain factors that can predict a child's future school achievement and his/her psychological adjustment, as well. What is more, it has been argued that the dimensions of psychosocial behavior should be included in children's with learning difficulties characteristics classification.

Children with and without LD are consistently found to differ in their motivational and behavioral profiles. For example, children with and without LD differ in their achievement motivation (Dunn \& Shapiro, 1999; Olivier \& Steenkamp, 2004; Pintrich, Anderman, \& Klobucar, 1994), helplessness (Sabatino, 1982; Thomas, 1979; Valas, 2001), depression (Colbert, Newman, Ney, \& Young, 1982; Dalley, \& Bolocofsky, 1992; Heath \& Ross, 2000), anxiety (Hoy et al., 1997; Rodriguez \& Routh, 1989), self-esteem (Riddick, Sterling, Farmer, \& Morgan, 1999), self-concept (Chapman, 1988a,b; Stanovich, Jordan, \& Perot, 1998), loneliness (Valas, 1999), locus of control (Rogers \& Saklofski, 1985), goal commitment (Bouffard \& Couture, 2003), goal importance (Sideridis, 2002; Sideridis \& Padeliadu, 2001), psychological disturbances (Greenway \& Milne, 1999; Gregg, Hoy, King, Moreland, \& Jagota, 1992), psychological adjustment (Grolnick \& Ryan, 1990), emotional disregulation (Masi, Brovedani, \& Poli, 1998), metacognition (Botsas \& Padeliadu, 2003; Palladino, Poli, Masi, \& Marcheschi, 2000), and self-regulation (Fulk, Brigham, \& Lohman, 1998).

Additionally, it has been found that, when psychosocial characteristics are assessed, the predictive validity to detect learning difficulties is really high (Sideridis et al., 2006).

Assessing students' school and social efficiency really contributes to spotting possible problems that make their adjustment and efficiency into their school and social environment difficult. As many studies showed (Forgan \& Vaughn, 2000; Hatzichristou \& Hopf, 1993; Tur-Kaspa et al., 1999) school achievement and adapting to school expectations depends on the degree of the student's psychosocial maturity and the satisfaction he/she gets from learning $\eta$ and his/her interactions with others in the school, family and social frame. As a result, both the way a child functions at school and the way he/she sees him/herself, his/her achievements and his/her acceptance by others are important factors that should be taken into consideration when planning appropriate intervention programs.

As to the topic of self-concept, quite a lot of children with LD display a poor academic self-concept. Other dimensions of their self-concept and their global self-concept do not seem to be affected to the same extent (Cosden \& McNamara, 1997).

On the other hand, empirical research has documented several aspects of psychosocial functioning in children and youngsters with LD. Behavior problems, self-concept, social relationships, and motivational factors are the topics that have been studied most (Beitchman \& Young, 1997; Kavale \& Forness, 1996). A lot of studies (Forgan \& Vaughn, 2000; Pearl, 1992; Tur-Kaspa \& Bryan, 1994), particularly on children with LD, have showed that most of the time these children possess inadequate social skills, difficulties in communicating and forming interpersonal relationships and show less positive social behaviors.

In addition, there are studies that mostly focus on these children's particular social difficulties, including self-perception (Chapman, 1988a,b), interpersonal skills, social relationships and communication (LaGreca, 
1987), social adjustment (Gresham, 1988), behavior inside and outside of the classroom, social cognition, causal attributions (Pearl, 1987) and taking up roles (Kitano et al., 1978).

Other studies support that these children have poor skills in decoding correctly and in a consistent way stimuli and hints that appear in every social occasion (Kavale \& Forness, 1996). About the hints, their difficulty is that they cannot interpret visual and auditory hints (facial expressions, intentions, messages etc.) (Most \& Greenback, 2000). These inadequate social skills and low social conception often cause significant problems to students with learning difficulties. One of these problems is their negative self-image, which leads to poor social contacts and isolation, which in turn lowers the level of their already low self-esteem, thus creating a vicious circle.

Research on causal attributions for academic success and failure shows divergent results (Bender \& Wall, 1994). It should be noted, though, that the relation between academic functioning on the one hand and self-concept, attributions, motivation to learn, and academic expectations on the other hand is said to be weak in the younger age groups (especially in children under 8 years old) (Cadieux, 1996). Looking at the field of social functioning, the perception of non-verbal social communication of children with LD tends to be less accurate (Nabuzoka \& Smith, 1995). These children also present deficits in their actual social behavior (Gallico et al., 1991), and are found to have a more problematic social position in their class (Kuhne \& Wiener, 2000).

Children with LD show different types of behavior problems (Gadeyne, Ghesquiere, \& Onghena, 2004; Osman, 2000; Willcutt \& Pennington, 2000). Attention problems and sometimes also hyperactive behavior seem the most prominent problems associated with LD, certainly at the younger ages (Kotkin, Forness, \& Kavale, 2001). Externalizing behavior problems are also often mentioned in relation to LD (Prior et al., 1999). As to internalizing behavior problems, the findings are not that clear. Some studies suggest that especially children with mathematical disabilities or non-verbal learning disabilities (NLD) present higher rates of internalizing behavior problems (Osman, 2000; Prior et al., 1999).

The relation between learning difficulties and emotional problems, even though it has already been pointed out, has not been clarified yet. It is indisputable that LD are related to emotional adjustment and interpersonal relationships. The impact of these problems when creating the children's and teenagers' with learning difficulties profile has led many scientists to suggest their inclusion into the definition of LD (Kavale \& Forness, 1996; Sideridis et al., 2006). The factors that that have been studied the most and are related to LD are negative feelings, stress over new or unfamiliar situations, low self-esteem and self-perception.

In addition, the importance of complex cognitive functions for academic success is well-established for typically achieving students as well as for those with LD (Meltzer, 1993; Pressley \& Woloshyn, 1995; Zimmerman, 1994). In recent years, a growing interest has been accrued to the role executive functions play in children's ability to understand written and spoken language, in their ability to solve arithmetic problems, as well as in their ability to continuously monitor and regulate their behavior (Hooper et al., 2002). Attention and focus are also considered to be important factors which contribute in a defining way to the possession of academic skills and knowledge, as well as to the ability to participate, in general, to the educational process. In other words, attention contributes to more complex skills, such selecting stimuli and attributes, neglecting irrelevant stimuli and suppressing inappropriate behavior when executing a cognition task (Alevriadou \& Giaouri, 2015a, 2015b; Fiducia \& O’Leary, 1990; Hunt \& Marshall, 2005; Sonuga-Barke et al., 2005). Attention interacts to a great extent with mnemonic ability and together they significantly affect school achievement. Less attention span has been constantly observed to children with learning difficulties (Korkman \& Pesonen, 1994). The main contribution to these children's achievement problems is the negative impact that these attention problems have on using problem solving strategies and approaching academic tasks (Smith, 2004).

Research findings support the view that executive functions and attention deficits are real and important for students with LD (Alevriadou \& Giaouri, 2015a,b; Borkowski, Estrada, Milstead, \& Hale, 1989). These difficulties are firstly reflected on the integration problems of cognitive processes involved in problem solving (e.g. perception, memory, attention and language) and secondly on the individual skills involved in reading and writing. Deficits in the organizational structures of language can be due to a wide range of cognitive processes including poor attention skills, limited vocabulary development, poor working memory skills, or faulty executive functioning skills (Feifer \& Defina, 2002). Perhaps no other academic endeavor presents a greater challenge for educators to remediate successfully than written language skills. Students are expected to write in a variety of styles, such as narrative, informative or persuasive, while simultaneously demonstrating their linguistic prowess through mastery of spelling, syntax, grammar, capitalization, punctuation, and organization of ideas (Feifer, 2013). In essence, the complexity of written language is twofold, as children must not only organize and tran- 
scribe the mental representations in a motoric manner, but they must also possess the mental capacity and cognitive flexibility to formulate their own thoughts.

Therefore, written expression can be frustrating and difficult for many primary school-aged students. Because writing can be cognitively overwhelming, physically exhausting, and time consuming for students with LD, they often develop negative attitudes towards writing, helplessness or anxiety. As a result, many students with LD put forth minimal effort when writing and avoid writing when possible (Garcia-Sanchez \& Fidalgo-Redondo, 2006).

The objective of the present study was to investigate the relationship between cognitive and psychosocial functioning in a sample of 44 Greek-speaking, $5^{\text {th }}$ grade students with writing disabilities. Since very little research has adopted the perspective of intertwined areas of psychosocial functioning, our study is an exploratory one.

\section{Method}

\subsection{Participants}

The present study involved a group of 44 Greek-speaking, $5^{\text {th }}$ grade students with no reported history of speech/ language, attention, neurological or hearing difficulties who participated in the study. The sex ratio in that group was approximately 1:1 (male:female). The children were referred by their teachers for evaluation to the Public Centre for Diagnosis and Support for Children with Special Educational Needs and Disability (Hellenic Ministry of Education, Research and Religious Affairs) in Kozani (a small sized city of 70,000 people), Greece, during the school year 2014-2015. The children were diagnosed with having writing disabilities, meeting the inclusionary criteria as described in the Diagnostic and Statistical Manual of Mental Disorder (DSM-IV, American Psychiatric Association, 1994). None of the children had psychopathology and/or attention deficit/hyperactivity disorder. Their age ranged from 10.7 to 11.7 years with a mean age of 11.2 years. All children were recruited from the same regular schools of average/middle socioeconomic status in Kozani, Greece (coming from economically and educationally upper/middle areas of the city and based on the teachers' reports (classification of the socioeconomic status were both fathers' occupation and the total income of the family).

\subsection{Measures}

a) Test of Detection and Investigation of Attention and Concentration for Elementary School Students (Simos, Mouzaki, \& Sideridis, 2007a). Its subscales ensure comprehensive coverage of the full range of attention and concentration associated with academic performance, including verbal and nonverbal tests, some of which were administered visually and some in an auditory manner. The subscales are:

\section{- Subscale of sustained auditory attention}

This subscale assesses the ability of focusing and retaining attention on predetermined verbal stimuli. Students listen to a series of words (i.e. watermelon, picture, soon, so, listen, apple...) which are presented at a pace of one word per second, for about three minutes. They are then asked to detect a particular word ("apple") from a series of irrelevant stimuli (such as "round", "now" and "point").

\section{- Subscale of sustained visual attention}

This subscale assesses the speed and accuracy in which students can investigate a thick array of small shapes, spot and write down a predetermined target-shape (a bell), under time pressure. The overall number of correctly spotted targets, of selecting non-targets and test completion time are assessed.

\section{- Range of auditory attention}

This subscale assesses the ability of short-term retention of sentences which are progressively extended based on both phonological and syntactical features (Wagner \& Torgesen, 1987). The assessor reads a sentence at a time (from a list of sentences which are progressively extended) and asks students to repeat it word by word.

\section{- Range of visual attention (positions in space)}

This subscale assesses the ability of short-term retention of a number (larger after every trial) of positions in a visual scene (a playground). The assessor shows the sequence of positions that the lead character of the story (duckling) visits each time and asks children to retrace the route.

The test scores are calculated by the final grades ( 0.1 to 1 ) per subscale using the tables with the norms by grade and sex percentiles (from 5 to 99, mean 50). The sum of the final scores of the subscales provides the Total Score of Attention. 
b) Test of Detection and Investigation of Executive Functions for Elementary School Students (Simos, Mouzaki, \& Sideridis, 2007b).

Its subscales ensure comprehensive coverage of the full range of executive functions associated with academic performance, including verbal and nonverbal tests, some of which were administered visually and some in an auditory manner. The subscales are:

- Subscale of tower: The task consists of three beads that vary in color and a board featuring three vertical pegs. Participants are shown a picture displaying the end position of the tower to be built. The participant's task is to move the beads across the three pegs to build the target tower in a specified number of moves. The task assesses spatial planning, rule learning, and inhibition of impulsive responding.

- Subscale of extended application of complex strategic replies: This test assesses the ability to implement a complex strategy of selecting answers to predetermined vocal stimuli. The person tested listens to a sequence of words which are presented at a pace of a word per second for about three minutes. The person tested has in front of them an answering sheet showing four kinds of fruit (a grape, an apple, a banana, a watermelon). They have to detect the pronunciation of particular words ("banana”, "watermelon”, "grape”), inhibiting the impulsive inclination to indicate the same picture when they hear "apple" (they have to indicate the banana) and "banana" (they have to indicate the apple), but answering in a "natural” way when hearing "grape" (they have to indicate the grape).

- Subscale of inductive thought: Nonverbal logical sequences (story \& geometric shapes), Verbal logical sequences, Nonverbal analogies (geometric shapes \& pictures), Verbal analogies.

The test scores are calculated by the final grades ( 0.1 to 1 ) per subscale using the tables with the norms by grade and sex percentiles (from 5 to 99, mean 50). The sum of the final scores of the subscales provides the Total Score of Executive Functions.

c) Test of Psychosocial Adjustment and Self-Report Scale (Hatzichristou et al., 2007).

It is an assessment scale that students aged 10 - 12 complete (D and F class). Its goal is to detect skills or deficits in the social and emotional field and school adjustment, as well as, difficulties concerning intrapersonal and interpersonal adjustment. It is assessed the actual children's evaluation of the behaviors that may prevent learning and adjustment.

The self-reference scale includes 115 questions-suggestions. These questions give the following five subscales:

- Social Sufficiency (So.S) Claiming Skills/Leadership (CL.S), Interpersonal Communication (IC), Cooperation with Peers (PC)

- School Sufficiency (SS) Motives (M), Organization/Planning (OP), Academic Effectiveness (AE), School Adaptation (SA)

- Emotional Sufficiency (ES) Self-Regulation (SR), Management of Emotions (EM), Stress Management (SM), Empathy (E)

- Self-perception (SP) Language Ability (LA), Mathematics Ability (MA), Learning Ability (LA), Self-Esteem (SE)

- Behavioral Problems (BP) Interpersonal Adjustment (IA), Personal Adjustment (PA), Hyperactivity/Attention Deficit (H/AD)

The values range from 20 low to 80 high with an average score of 40 - 60. When in tests the Standard Score(s) is/are $<43$, then it is considered that the child has some difficulties in the specific subscale. The only exception is the Behavioral Problems (BP) subscale, where if there are Standard Scores $>57$ then it is considered that the child has problems.

\subsection{Procedure}

The tests and the consent form were reviewed and approved by the Institutional Research Ethics Board University of Western Macedonia, Greece. Then, an informed consent was signed by the parents of the students at the Public Centre for Diagnosis and Support for Children with Special Educational Needs and Disability (Hellenic Ministry of Education, Research and Religious Affairs) in Kozani, Greece. The participants were informed of the research purpose orally prior to data collection. They underwent 2 days of evaluation. Total administration time varied from participant to participant, but required between 1 and $1.30 \mathrm{~h}$ and two sessions for each participant. The sessions took place in a quiet room. 


\subsection{Statistical Analysis}

For the analysis of the results the statistical program SPSS (V19) for Windows was used. At first we examined the children's with LD average scores in the Self-Reference Scale. The t test for independent samples was used for the detection of possible variations between the two experimental groups. The Pearson correlation statistical analysis was also used between the Self-Report Scale, the Test of Detection and Investigation of Attention and Concentration and the Test of Detection and Investigation of Executive Functions. Finally, regression analysis was used to be determined if the subscales of the Test of Detection and Investigation of Attention and Concentration and the Test of Detection and Investigation of Executive functions can predict the children's answers in the Self-Reference Scale.

\section{Results}

In the dimensions of the Social Sufficiency (So.S) and Behavioral Problems (BP) subscales there are no difficulties according to the children's self-assessment average scores. There are difficulties in the School Sufficiency (SS) subscale (Means 38.77), as well as in the dimensions; Organization/Planning (OP) (Means 24.06) and Academic effectiveness (AE) (Means 40.02). There are also difficulties in the Emotional Sufficiency (ES) subscale (Means 41.52) and in the dimension of Self-regulation (SR) (Means 29.20). Finally, there are also difficulties in the Self-perception (SP) subscale (Means 36.61) and in the dimensions: Learning Ability (LA) Self-esteem (SE) (Means 26.86) and Self-esteem (SE) (Means 42.25).

In the t test there was a statistically significant gender impact only in the following subscales of the Test of Psychosocial Adjustment and Self-Report Scale:

- In School Sufficiency: girls $($ Means $=42.13$ S.D. $=5.073)$ had better scores than boys $($ Means $=37.90$ S.D. $=$ 6.851), $t(42)=-2.326, p=0.025$.

- In Language Ability: girls $($ Means $=45.04$. S.D. $=6.298)$ had better scores than boys $($ Means $=41.50$ S.D. $=$ 4.372), $t(42)=-2.169 p=0.036$.

Significant is at the 0.05 level (2-tailed).

The findings of the study show averagely significant Pearson correlations only between the following subscales of the Test of Detection and Investigation of Attention and Concentration and the Self-Report Scale (see Table 1).

The findings of the study show averagely significant correlations only between the following subscales of the Test of Detection and Investigation of Executive functions and the Self-Report Scale (see Table 2).

From the use of Regression Analysis came out that from the subscales of the Test of Detection and Investigation of Attention and Concentration only the Total Score of Attention can predict Emotional Sufficiency (ES) ( $t$ $=2.001, p<0.05)$ and Self-perception (SP) $(t=2.072, p<0.05)$, whereas the subscales of the Test of Detection and Investigation of Executive functions do not have a predictive value for the Self-Report Scale.

Table 1. Pearson correlations between the subscales of the Test of Detection and Investigation of Attention and Concentration and the Self-Report Scale.

\begin{tabular}{|c|c|c|c|}
\hline $\begin{array}{l}\text { Subscales of the Test of Psychosocial } \\
\text { Adjustment/Self-Report Scale }\end{array}$ & $\begin{array}{l}\text { Total score of } \\
\text { attention }\end{array}$ & Range of auditory attention & Range of visual attention \\
\hline Interpersonal communication & $0.320\left(^{*}\right)$ & $0.382\left(^{*}\right)$ & \\
\hline Academic effectiveness & $0.435\left(^{* *}\right)$ & $0.476\left(^{* *}\right)$ & \\
\hline Empathy & $0.377\left(^{*}\right)$ & & $0.304\left({ }^{*}\right)$ \\
\hline Self-esteem & $0.304\left(^{*}\right)$ & & \\
\hline Language ability & $0.391\left(^{* *}\right)$ & $0.379\left({ }^{*}\right)$ & \\
\hline Mathematics ability & $0.415\left(^{* *}\right)$ & $0.338\left(\left(^{*}\right)\right.$ & \\
\hline Social sufficiency & & $0.353\left(^{*}\right)$ & \\
\hline Cooperation with peers & & $0.347\left(\left(^{*}\right)\right.$ & \\
\hline School sufficiency & & $0.335\left(^{*}\right)$ & \\
\hline
\end{tabular}

${ }^{*}$ Correlation is significant at the 0.05 level (2-tailed). ${ }^{* *}$ Correlation is significant at the 0.01 level (2-tailed). 
Table 2. Pearson correlations between the subscales of the Test of Detection and Investigation of Executive functions the Self-Report Scale.

\begin{tabular}{|c|c|c|c|c|c|}
\hline $\begin{array}{l}\text { Subscales of the Test of Psychosocial } \\
\text { Adjustment/Self-Report Scale }\end{array}$ & $\begin{array}{l}\text { Nonverbal logical } \\
\text { sequences (stories) }\end{array}$ & $\begin{array}{l}\text { Verbal logical } \\
\text { sequences }\end{array}$ & $\begin{array}{c}\text { Nonverbal } \\
\text { analogies (pictures) }\end{array}$ & $\begin{array}{l}\text { Verbal } \\
\text { analogies }\end{array}$ & $\begin{array}{l}\text { Total score of ex- } \\
\text { ecutive functions }\end{array}$ \\
\hline School sufficiency & $0.375\left(^{*}\right)$ & & & & \\
\hline Motives & $0.302\left({ }^{*}\right)$ & & & & \\
\hline Academic effectiveness & $0.318\left(^{*}\right)$ & $0.308\left(^{*}\right)$ & & & \\
\hline Language ability & & $0.390\left(^{* *}\right)$ & & & \\
\hline Mathematics ability & $0.387\left(^{* *}\right)$ & $0.330\left(^{*}\right)$ & $0.430\left(^{* *}\right)$ & $0.308\left(^{*}\right)$ & $0.432\left(^{* *}\right)$ \\
\hline
\end{tabular}

${ }^{*}$ Correlation is significant at the 0.05 level (2-tailed). ${ }^{* *}$ Correlation is significant at the 0.01 level (2-tailed).

\section{Discussion}

Assessing students, in a synchronic level, helps us create a complex profile of cognitive and social-emotional characteristics, which are linked to difficulties of a certain type during their school course.

The results of this study indicate that there are correlations between cognitive (attention, focus and executive functions) and school, social and emotional parameters. The Total Score of Attention is related to the social, school and emotional adequacy and has predictive value concerning emotional adequacy and school self-perception. More specifically, the span of auditory and visual attention (number of elements that can be detained in consciousness to choose from and further analyze or store for a long time) appears to be related not only to school effectiveness and self-perception of school skills, but also to social adequacy, interpersonal adjustment and empathy.

The main contribution to children's with writing disabilities problems is perhaps the negative influence that attention deficits have on the use of organizing strategies, planning and solving cognitive problems while writing. This influence seriously affects and makes the strategic approach of academic tasks difficult for them (Smith, 2004).

The ability to understand written and spoken language requires, among other things, long-term focus of attention to a predetermined sensory pathway (i.e. perspective during writing), systematic application of the crucial stimuli features (i.e. on a phonological, lexical and semantic level) and the ability of selective processing of predetermined stimuli features while neglecting irrelevant features. Finally, it also requires conscious short-term retention of a series of data in order for it to be integrated with previous data which are meaningfully linked (Bull \& Johnson, 1997; Cowan, 1993; Fiducia and O’Leary, 1990; Hunt \& Marshall, 2005; Sharipo, 1994).

Executive functions are mostly related to school efficiency and self-perception of school skills in Language and Mathematics. On the other hand, the Total Score of Executive Functions is only related to students' perception concerning their achievement in Mathematics.

Furthermore, executive functions also play an important role in a child's cognitive functioning, behavior, emotional control and social interaction (Anderson, 2002). Their role in school learning is widely recognized by modern literature (Sternberg, 1998).

According to many studies, students with learning difficulties have trouble organizing and planning their study, paying attention during class, focusing attention on written and verbal stimuli and insisting on completing a task (Baker \& Brown, 1984; Botsas \& Padeliadu, 2003). Research data support our view that the students' with learning difficulties metacognitive deficits are real and significant (Borkowski et al., 1989). They also affect, to a great extent, those students' achievement in every cognitive task throughout their entire school life. As learning is a difficult process for them, they often face low levels of school effectiveness (Dunn \& Shapiro, 1999). Most of the time, these perceptions of low effectiveness and self-control of their behavior are accompanied by low school achievement expectations, quitting school tasks and being reluctant to try harder and process more deeply.

Teaching of cognitive and metacognitive strategies reinforces standard behavior, familiarizes students with learning disabilities with their abilities and inabilities and contributes to the development of self-regulatory behaviors during writing (Troia, 2002). Self-regulatory strategies, in particular, such as target-setting, self-control, self-assessment and self-reinforcement, strategies which are related to written language stages, strongly affect 
students’ performance during writing (Harris \& Graham, 1996; Harris et al., 2003).

It has also been proved that students with poor school achievement appear to have low self-perception concerning their secondary abilities at school and in the way they perceive themselves in general, as well (Sideridis et al., 2006; Valentine et al., 2004).

As far as the role of motives and their developmental course is concerned, it seems that the sample students' perceptions about their abilities are still positive. But studies mention that their perceptions become more and more negative as they grow old, particularly during Junior High School, as these teenagers better understand their difficulties compared to their classmates (Dweck \& Elliott, 1983).

With regard to the issue of gender specificity, the $t$ test analyses revealed that boys scored worse than girls on the Self-perception (especially on Language Ability subscale) and School Sufficiency variables according to the Self-Report Scale. These findings are supported by other studies (Fischer, Schult, \& Hell, 2013; Pomerantz et al., 2002). However, further investigation is required in order to draw reliable conclusions about the role of the gender.

Lastly, the research usefulness of the tests presented refers to the assessment of the students; level and developmental pace in a wide range of factors which are related to learning difficulties. We have, thus, the opportunity to plan a smart and based on facts educational program for every student through comparative analysis of his/her achievement in various tests, including cognitive, learning and social criteria. Furthermore, information that comes from the actual child is valuable, especially when intrapersonal adjustment; motives and emotional adjustment are assessed, as these factors cannot be easily observed by teachers or parents. This information can really help a special educator assess the degree of support and make it easier to form a relationship of collaboration with the child, enhancing his/her psychosocial and school adjustment.

Several limitations of this study may have affected the overall results and interpretations. Firstly, this study was limited by its small sample size. A larger, more diverse sample would have been beneficial for our results in order to ensure a representative distribution of the population and to be considered representative of groups of children to whom our results will be generalized or transferred. Ideally, the number of participants would have been more evenly distributed across years in school/age/nationality/etc. Secondly, the lack of a control group may suggest alternative explanations to improved expository compositions. Although the brevity of the study attempted to control extraneous variables, without a true control group practice effects could not be parceled out. Future research should attempt to replicate these results across different writing compositions (e.g., persuasive, narrative, opinion) exploring simultaneously additional cognitive functioning capacities, which are critical for successful writing. However, this study is a significant attempt to provide a stepping-stone for further research in the area of attention and concentration and their relationship with writing in special populations.

Although we did not aim to investigate causal relationships between cognitive factors problems and psychosocial problems, this study resulted in correlational findings that may prove to be of utmost relevance for the group of children with learning problems. Studying several psychosocial and cognitive variables simultaneously in relation to learning problems, accounting for their interrelations, and comparing different groups of children with learning problems on these variables, we were able to shed a new light on a literature that is dominated by univariate analyses. In our opinion, this will prove to be a very fruitful path of research in the future.

\section{References}

Alevriadou, A., \& Giaouri, S. (2015a). Children with Writing Disabilities: Revisiting the Role of Attention and Concentration. In Costa, A. and Villalba, E. (Eds.), Horizons in Neuroscience Research (Vol. 20, pp. 101-114). Nova Science Publishers, Inc.

Alevriadou, A., \& Giaouri, S. (2015b). The Impact of Executive Functions on the Written Language Process: Some Evidence from Children with Writing Disabilities. Journal of Psychologists and Counsellors in Schools, 25, 24-37. http://dx.doi.org/10.1017/jgc.2015.3

Altemeier, L., Jones, J., Abbott, R. D., \& Berninger, V. W. (2006). Executive Functions in Becoming Writing Readers and Reading Writers: Note Taking and Report Writing in Third and Fifth Graders. Developmental Neuropsychology, 29, 161-73. http://dx.doi.org/10.1207/s15326942dn2901_8

Beitchman, J. H., \& Young, A. (1997). Learning Disorders with a Special Emphasis on Reading Disorders: A Review of the Past 10 Years. Journal of the American Academy of Child and Adolescent Psychiatry, 36, 1020-1032. http://dx.doi.org/10.1097/00004583-199708000-00009

Bender, W. B., \& Wall, M. E. (1994). Social-Emotional Development of Students with Learning Disabilities. Learning Disability Quarterly, 17, 323-341. http://dx.doi.org/10.2307/1511128 
Borkowski, J. G., Estrada. M., Milstead, M., \& Hale, C. A. (1989). General Problem-Solving Skills: Relation between Metacognition and Strategic Processing. Learning Disability Quarterly, 12, 57-70. http://dx.doi.org/10.2307/1510252

Botsas, G., \& Padeliadu, S. (2003). Goal Orientation and Reading Comprehension Strategy Use among Students with and without Reading Difficulties. International Journal of Educational Research, 39, 477-495.

http://dx.doi.org/10.1016/j.ijer.2004.06.010

Botsas, G., \& Padeliadu, S. (2003). Goal Orientation and Reading Comprehension Strategy Use among Students with and without Reading Difficulties. International Journal of Educational Research, 39, 477-495. http://dx.doi.org/10.1016/j.ijer.2004.06.010

Bouffard, T., \& Couture, N. (2003). Motivational Profile and Academic Achievement among Students Enrolled in Different Schooling Tracks. Educational Studies, 29, 19-38. http://dx.doi.org/10.1080/03055690303270

Cadieux, A. (1996). Psychometric Properties of a Pictorial Self-Concept Scale among Young Learning Disabled Pupils. Psychology in the Schools, 33, 221-229. http://dx.doi.org/10.1002/(SICI)1520-6807(199607)33:3<221::AID-PITS5>3.0.CO;2-S

Chapman, J. W. (1988a). Cognitive-Motivational Characteristics and Academic Achievement of Learning Disabled Children: A Longitudinal Study. Journal of Educational Psychology, 80, 357-365. http://dx.doi.org/10.1037/0022-0663.80.3.357

Chapman, J. W. (1988b). Learning Disabled Children’s Self-Concepts. Review of Educational Research, 58, $347-371$. http://dx.doi.org/10.3102/00346543058003347

Colbert, P., Newman, B., Ney, P., \& Young, J. (1982). Learning Disabilities as a Symptom of Depression in Children. Journal of Learning Disabilities, 15, 333-336. http://dx.doi.org/10.1177/002221948201500605

Cosden, M. A., \& McNamara, J. (1997). Self-Concept and Perceived Social Support among College Students with and without Learning Disabilities. Learning Disability Quarterly, 20, 2-12. http://dx.doi.org/10.2307/1511087

Dalley, M. B., \& Bolocofsky, D. N. (1992). Depressive Symptomatology, Attributional Style, Dysfunctional Attitude, and Social Competency in Adolescents with and without Learning Disabilities. School Psychology Review, 21, 444-459.

Dunn, P. B., \& Shapiro, S. K. (1999). Gender Differences in the Achievement Goal Orientations of ADHD Children. Cognitive Therapy and Research, 23, 327-344. http://dx.doi.org/10.1023/A:1018747716137

Dweck, C. S., \& Elliott, E. S. (1983). Achievement Motivation. In P. H. Mussen (Gen. Ed.), \& E. M. Hetherington (Ed.), Handbook of Child Psychology (Vol. 4, pp. 643-691). New York: Wiley.

Feifer, S. (2013). Psychopathology of Disorders of Written Expression and Dysgraphia. In A. S. Davis (Ed.), Psychopathology of Childhood and Adolescence (pp. 145-157). New York: Springer Publishing Company.

Feifer, S., \& De Fina, P. (2002). The Neuropsychology of Written Language Disorders: Diagnosis and Intervention. Middletown, MD: School Neuropsych Press.

Fiducia, D., \&. O’Leary D. S. (1990). Development of a Behavior Attributed to the Frontal Lobes and the Relationship to Other Cognitive Functions. Developmental Neuropsychology, 6, 85-94. http://dx.doi.org/10.1080/87565649009540452

Fischer, F., Schult, J., \& Hell, B. (2013). Sex Differences in Secondary School Success: Why Female Students Perform Better. European Journal of Psychology of Education, 28, 529-543. http://dx.doi.org/10.1007/s10212-012-0127-4

Forgan, J. W., \& Vaughn, S. (2000). Adolescents with and without LD Make the Transition to Middle School. Journal of Learning Disabilities, 33, 26-32. http://dx.doi.org/10.1177/002221940003300107

Fulk, B. M., Brigham, F. J., \& Lohman, D. A. (1998). Motivation and Self-Regulation: A Comparison of Students with Learning and Behavior Problems. Remedial and Special Education, 19, 300-309. http://dx.doi.org/10.1177/074193259801900506

Gadeyne, E., Ghesquiere, P., \& Onghena, P. (2004). Psychosocial Functioning of Young Children with Learning Problems. Journal of Child Psychology and Psychiatry, 45, 510-521. http://dx.doi.org/10.1111/j.1469-7610.2004.00241.x

Gallico, R. P., Thomas, J. B., \& Brob, C. S. (1991). Emotional and Behavioural Problems in Children with Learning Disabilities. San Diego, CA: Singular Publishing Group, Inc.

Garcia-Sanchez, J.-N., \& Fidalgo-Redondo, R. (2006). Effects of Two Types of Self-Regulatory Instruction Programs on Students with Learning Disabilities in Writing Products, Processes, and Self-Efficacy. Learning Disability Quarterly, 29, 181-211. http://dx.doi.org/10.2307/30035506

Garner, R. (1988). Metacognition and Reading Comprehension. Norwood, NJ: Ablex.

Greenway, P., \& Milne, L. (1999). Relationship between Psychopathology, Learning Disabilities, or both and WISC-III Subtest Scatter in Adolescents. Psychology in the Schools, 36, 103-108. http://dx.doi.org/10.1002/(SICI)1520-6807(199903)36:2<103::AID-PITS2>3.0.CO;2-Q

Gregg, N., Hoy, C., King, M., Moreland, C., \& Jagota, M. (1992). The MMPI-2 Profile of Adults with Learning Disabilities in University and Rehabilitation Settings. Journal of Learning Disabilities, 25, 386-395. 
http://dx.doi.org/10.1177/002221949202500607

Gresham, F. M. (1988). Social Competence and Motivational Characteristics of Learning Disabled Students. In M. Wang, M. Reynolds, \& H. Walberg (Eds.), Handbook of Special Education: Research and Practice (Vol. 2, pp. 283-302). Oxford: Pergamon.

Grolnick, W. S., \& Ryan, R. M. (1990). Self-Perceptions, Motivation, and Adjustment in Children with Learning Disabilities: A Multiple Group Comparison Study. Journal of Learning Disabilities, 23, 177-184.

http://dx.doi.org/10.1177/002221949002300308

Hatzichristou, C., \& Hopf, D. (1993). Students with Learning Disabilities: Academic and Psychosocial Aspects of Adaptation. School Psychology International, 14, 43-56. http://dx.doi.org/10.1177/0143034393141003

Hatzichristou, C., Polychroni, P., Bezevegis, H., \& Miller, K. (2007). Test of Psychosocial Adjustment and Self-Report Scale. Athens: Greek Ministry of Education. (In Greek)

Heath, N. L., \& Ross, S. (2000). Prevalence and Expression of Depressive Symptomatology in Students with and without Learning Disabilities. Learning Disability Quarterly, 23, 24-36. http://dx.doi.org/10.2307/1511097

Hooper, S. R., Swartz, C., Wakwly, M., de Kruif, R., \& Montgomery, J. (2002). Executive Functions in Elementary School Children with and without Problems in Written Expression. Journal of Learning Disabilities, 35, 59-68.

http://dx.doi.org/10.1177/002221940203500105

Hoy, C., Gregg, N., Wisenbaker, J., Manglitz, E., King, M., \& Moreland, C. (1997). Depression and Anxiety in Two Groups of Adults with Learning Disabilities. Learning Disability Quarterly, 20, 280-291. http://dx.doi.org/10.2307/1511226

Hunt, N., \& Marshall, K. (2005). Exceptional Children and Youth. Boston, MA: Houghton Mifflin.

Kavale, K. A., \& Forness, S. R. (1996). Social Skill Deficits and Learning Disabilities: A Meta-Analysis. Journal of Learning Disabilities, 29, 226-237. http://dx.doi.org/10.1177/002221949602900301

Kitano, M., Stiehl, J., \& Cole, J. (1978). Role Taking: Implications for Special Education. The Journal of Special Education, 12, 59-74. http://dx.doi.org/10.1177/002246697801200110

Korkman, M., \& Pesonen, A. E. (1994). A Comparison of Neuropsychological Test Profiles of Children with AttentionDeficit Hyperactivity Disorder and/or Learning Disorder. Journal of Learning Disabilities, 27, 383-392. http://dx.doi.org/10.1177/002221949402700605

Kotkin, R. A., Forness, S. R., \& Kavale, K. A. (2001). Comorbid ADHD and Learning Disabilities: Diagnosis, Special Education, and Intervention. In D. P. Hallagan, \& B. K. Keogh (Eds.), Research and Global Perspectives in Learning Disabilities (pp. 43-63). Mahwah, NJ: Lawrence Erlbaum Associates.

Kuhne, M., \& Wiener, J. (2000). Stability of Social Status of Children with and without Learning Disabilities. Learning Disability Quarterly, 23, 64-75. http://dx.doi.org/10.2307/1511100

LaGreca, A. M. (1987). Children with Learning Disabilities: Interpersonal Skills and Social Competence. Journal of Reading, Writing, and Learning Disabilities International, 3, 167-185. http://dx.doi.org/10.1080/0748763870030207

Lyon, G. R., Fletcher, J. M., \& Barnes, M. C. (2003). Learning Disabilities. In E. J. Mash, \& R. A. Barkley (Eds.), Child Psychopathology (pp. 390-435). New York: Guilford Press.

Masi, G., Brovedani, P., \& Poli, P. (1998). School Failure in Early Adolescence: The Psychopathological Risk. Child Psychiatry and Human Development, 29, 127-140. http://dx.doi.org/10.1023/A:1025036032678

Merrell, K. W. (1998). Assessing Social Skills and Peer Relations. In H. Booney Vance (Ed.), Psychological Assessment of Children. New York: John Wiley.

Most, T., \& Greenback, A. (2000). Auditory, Visual and Auditory-Visual Perception of Emotions by Adolescents with and without Learning Disabilities and Their Relationship to Social Skills. Learning Disabilities Research and Practice, 15, 171-178. http://dx.doi.org/10.1207/SLDRP1504_1

Nabuzoka, D., \& Smith, P. K. (1995). Identification of Expressions of Emotions by Children with and without Learning Disabilities. Learning Disabilities Research and Practice, 10, 91-101.

Olivier, M. A. J., \& Steenkamp, D. S. (2004). Attention-Deficit/Hyperactivity Disorder: Underlying Deficits in Achievement Motivation. International Journal for the Advancement of Counselling, 26, 47-63.

http://dx.doi.org/10.1023/B:ADCO.0000021549.40409.c4

Osman, B. B. (2000). Learning Disabilities and the Risk of Psychiatric Disorders in Children and Adolescents. In L. L. Greenhill (Ed.), Learning Disabilities. Implications for Psychiatric Treatment. Washington DC: American Psychiatric Press, Inc.

Palladino, P., Poli, P., Masi, G., \& Marcheschi, M. (2000). The Relation between Metacognition and Depressive Symptoms in Preadolescents with Learning Disabilities: Data in Support of Borkowski’s Model. Learning Disabilities Research \& Practice, 15, 142-148. http://dx.doi.org/10.1207/SLDRP1503_4 
Pearl, R. (1987). Social Cognitive Factors in Learning-Disabled Children’s Social Problems. In S. J. Ceci (Ed.), Handbook of Cognitive, Social, and Neuropsychological Aspects of Learning Disabilities (pp. 273-294). Hillsdale, NJ: Erlbaum.

Pearl, R. (1992). Psychosocial Characteristics of Learning Disabled Students. In N. N. Singh, \& I. L. Beale (Eds.), Learning Disabilities: Nature, Theory, and Treatment (pp. 96-125). San Diego: Academic Press.

http://dx.doi.org/10.1007/978-1-4613-9133-3 4

Pintrich, P. R., Anderman, E. M., \& Klobucar, C. (1994). Intraindividual Differences in Motivation and Cognition in Students with and without Learning Disabilities. Journal of Learning Disabilities, 27, 360-370. http://dx.doi.org/10.1177/002221949402700603

Pomerantz, E. M., Altermatt, E. R., \& Saxon, J. L. (2002). Making the Grade but Feeling Distressed: Gender Differences in Academic Performance and Internal Distress. Journal of Educational Psychology, 94, 396-404.

http://dx.doi.org/10.1037/0022-0663.94.2.396

Prior, M., Smart, D., Sanson, A., \& Oberklaid, F. (1999). Relationships between Learning Difficulties and Psychological Problems in Preadolescent Children from a Longitudinal Sample. Journal of the American Academy of Child and Adolescent Psychiatry, 38, 429-436. http://dx.doi.org/10.1097/00004583-199904000-00016

Riddick, B., Sterling, C., Farmer, M., \& Morgan, S. (1999). Self-Esteem and Anxiety in the Educational Histories of Adult Dyslexic Students. Dyslexia, 5, 227-248.

http://dx.doi.org/10.1002/(SICI)1099-0909(199912)5:4<227::AID-DYS146>3.0.CO;2-6

Rodriguez, C. M., \& Routh, D. K. (1989). Depression, Anxiety, and Attributional Style in Learning Disabled and Non-Learning Disabled Children. Journal of Clinical Child Psychology, 18, 299-304. http://dx.doi.org/10.1207/s15374424jccp1804_2

Rogers, H., \& Saklofski, D. H. (1985). Selfconcepts, Locus of Control and Performance Expectations of LD Children. Journal of Learning Disabilities, 18, 273-277. http://dx.doi.org/10.1177/002221948501800505

Sabatino, D. A. (1982). Research on Achievement Motivation with Learning Disabled Populations. Advances in Learning and Behavioral Disabilities, 1, 75-116.

Sideridis, G. D. (2002). Goal Importance and Students at Risk of Having Language Difficulties: An Underexplored Aspect of Student Motivation. Journal of Learning Disabilities, 35, 343-356. http://dx.doi.org/10.1177/00222194020350040501

Sideridis, G. D., \& Padeliadu, S. (2001). The Motivational Determinants of Elementary School Students at Risk of Having Reading Difficulties: An Application of Planned Behavior Theory with Goal Importance. Remedial and Special Education, 22, 268-297. http://dx.doi.org/10.1177/074193250102200502

Sideridis, G., Morgan, P. L., Botsas, G., Padeliadu, S., \& Fuchs, D. (2006). Identifying Students with or at Risk for Learning Disabilities Based on Motivation, Metacognition and Psychopathology: A ROC Analysis. Journal of Learning Disabilities, 39, 215-229. http://dx.doi.org/10.1177/00222194060390030301

Simos, P., Mouzaki, A., \& Sideridis, G. (2007a). Test of Detection and Investigation of Attention and Concentration for Elementary School Students. Athens: Greek Ministry of Education. (In Greek)

Simos, P., Mouzaki, A., \& Sideridis, G. (2007b). Test of Executive Function for Elementary School Students. Athens: Greek Ministry of Education. (In Greek)

Smith, C. R. (2004). Learning Disabilities. The Interaction of Students and Their Environments (5th ed.). Boston, MA: Allyn and Bacon.

Sonuga-Barke, E. J., Auerbach, J., Campbell, S. B., Daley, D., \& Tompson, M. (2005). Varieties of Preschool Hyperactivity: Multiple Pathways from Risk to Disorder. Developmental Science, 8, 141-150.

http://dx.doi.org/10.1111/j.1467-7687.2005.00401.x

Stanovich, P. J., Jordan, A., \& Perot, J. (1998). Relative Differences in Academic Selfconcept and Peer Acceptance among Students in Inclusive Classrooms. Remedial and Special Education, 19, 120-125. http://dx.doi.org/10.1177/074193259801900206

Thomas, A. (1979). Learned Helplessness and Expectancy Factors: Implications for Research in Learning Disabilities. Review of Educational Research, 49, 208-221. http://dx.doi.org/10.3102/00346543049002208

Tur-Kaspa, H., \& Bryan, T. H. (1994). Social Information: Processing Skills of Students with Learning Disabilities. Learning Disabilities Research and Practice, 9, 12-23.

Tur-Kaspa, H., Margalit, M., \& Most, T. (1999). Reciprocal Friendship, Reciprocal Rejection and Socioemotional Adjustment: The Social Experiences of Children with Learning Disorders over a One-Year Period. European Journal of Special Needs Education, 14, 37-48. http://dx.doi.org/10.1080/0885625990140104

Valas, H. (1999). Students with Learning Disabilities and Low Achieving Students: Peer Acceptance, Loneliness, Self-Esteem, and Depression. Social Psychology of Education, 3, 173-192. http://dx.doi.org/10.1023/A:1009626828789

Valas, H. (2001). Learned Helplessness and Psychological Adjustment: Effects of Learning Disabilities and Low Achieve- 
ment. Scandinavian Journal of Educational Research, 45, 101-114. http://dx.doi.org/10.1080/00313830120052705

Valentine, J. C., DuBois, D. L., \& Cooper, H. (2004). The Relation between Self-Beliefs and Academic Achievement: A Systematic Review. Educational Psychologist, 39, 111-133. http://dx.doi.org/10.1207/s15326985ep3902__3

Willcutt, E. G., \& Pennington, B. F. (2000). Psychiatric Comorbidity in Children and Adolescents with Reading Disability. Journal of Child Psychology and Psychiatry, 41, 1039-1048. http://dx.doi.org/10.1111/1469-7610.00691 